\title{
Epidemiological Aspects of kidney Failure in Hospitalized Children in Brazil
}

\section{Mangia CMF* and Andrade MC}

Department of Pediatrics, Escola Paulista de Medicina, Universidade Federal de São Paulo, Brazil

\begin{abstract}
Objective: The aim of this study is to evaluate the epidemiology, costs and outcome of children's kidney failure in Brazil.

Methods: The study is an observational cohort study based in national govern database. Data were collected from all hospitals affiliated to Brazilian unified health system (SUS). We analyzed all children from neonatal period to 19 years old with diagnosis of renal failure based on the 10th revision of the International Classification of Diseases (ICD-10).

Results: Demographic data were collected in eight cohorts from 1998 to 2007. There were 666.725 hospital admissions by kidney disease and 43,174 admissions by kidney failure. The mean of mortality rate, $4 \%$ in these cohorts. The admissions and mortality rate have been constant with high mortality under the age of 1 year since 1998. The incidence in boys was higher than in girls but was not significant $(p>0.05)$. The mean of length of stay was 9.55 days. The mean of annual costs was $\$ 5,075,641$ million and $\$ 588$ dollars per patient. In addition, the congenital malformations of the urinary system presented a coefficient of incidence in 1999 of the $0.08 / 1000$ inhabitants or 4 fold less than 2005 (0.44/1000).
\end{abstract}

Conclusion: Kidney failure is a prevalent healthy problem that affects children from neonatal period to adolescence and presents high post natal mortality. Renal failure is associated to a large spectrum of different ethiologies and different levels of morbidity and consequent impact on the outcome. On account of this early diagnosis improvement and treatments would be established.

Keywords: Acute kidney failure; Chronic kidney failure; Epidemiology; Child outcome costs

\section{Introduction}

Renal failure could be refered to temporary or permanent damage to the kidneys that results in loss of normal kidney function. In recent revisions and textbooks, the concepts of kidney failure are stratified in two different types - acute and chronic [1]. The diagnosis criteria to chronic failure can be considered as slow progression of renal disease over at least three months and may lead to permanent renal failure. There is no consensus definition on acute renal failure (ARF) and more that 30 different definitions have been used in the literature [2]. The current concept of acute kidney dysfunction focus the most severe forms with severe degree of kidney function like as azotemia and anuria [1]. This problem is important in critical care setting where acute kidney failure is a common form of organ dysfunction associated with high mortality [1]. In infants and children several diseases congenital or acquired have had relationship with acute or chronic renal failure but there is a lack of information on epidemiology and overall outcome of renal failure in pediatric population [3-5]. The aim of this study is to evaluate the epidemiological aspects and hospital morbidity associated to kidney failure in Brazilian children and its association with mortality based in a national and public database from 1998 through 2007.

\section{Methods}

\section{Source of data}

The study is exploratory and descriptive, based in hospital information system of hospital morbidity database (Tabnet) of the Unified Health System (DATASUS) with public access including all public hospitals corresponding to $80 \%$ of all hospital admissions in Brazil [6].

\section{Demographic characteristics of Brazilian population}

We obtained national population resident and birth rate [7] in
Brazil based on census and estimation from the Brazilian Institute of Geography and Statistics (IBGE) (Table 1).

\section{Case Selection and Definitions}

The cause of hospitalization considered was the main diagnosis of kidney failure that is discriminated in the database with codes from the International Classification of Diseases, tenth Revision. We analyzed from 1998 through 2007 all admissions associated to acquired and congenital renal disease and renal failure in Brazil: code N00-08; code 10-16; N17- 19 and code Q60-64 (Appendix 1). Hospital discharge information in the database include the following: geographic location of admission, ICD 10 chapter, ICD 10 morbidity list, gender, age-group, year and month of admission, total admissions, admissions mean, annual direct cost associated with hospital and medical assistance, direct individual costs, total hospital lengh of stay (LOS), LOS mean, overall mortality and mortality rate. In the secondary database for newborns, the same informations above are included plus gestational age, birth weight. The overall mortality in the period was analyzed by discharge and the mortality rate in the database is calculated by ratio between the number of deaths and admissions in the year or month considered, multiplied by 100 . Early neonatal mortality was considered deaths in early neonatal period (within first week of life). Late neonatal

*Corresponding author: Cristina Malzoni Ferreira Mangia, Rua dos Otonis, 880 apto 83, CEP 04025-002, São Paulo, Brazil, Tel/Fax: 55-11-55759276; E-mail: crismangia@netscape.net

Received: March 14, 2016; Accepted: March 30, 2016; Published: April 06, 2016

Citation: Mangia CMF, Andrade MC (2016) Epidemiological Aspects of kidney Failure in Hospitalized Children in Brazil. J Nephrol Ther 6: 245. doi:10.4172/21610959.1000245

Copyright: (c) 2016 Mangia CMF, et al. This is an open-access article distributed under the terms of the Creative Commons Attribution License, which permits unrestricted use, distribution, and reproduction in any medium, provided the original author and source are credited. 


\begin{tabular}{|l|l|}
\hline Admissions mean $\mathbf{\pm} \mathbf{D P}$ & \\
\hline $\mathbf{2 8}$ days-1 year & $623.6 \pm 25.5$ \\
\hline 1 -4 years & $1384.4 \pm 70$ \\
\hline $5-9$ years & $1662.8 \pm 152.7$ \\
\hline $10-14$ years & $2081.8 \pm 258.1$ \\
\hline $15-19$ years & $28822 \pm 59.4$ \\
\hline Male $-\mathrm{N}$ (\%) & \\
\hline $\mathbf{2 8}$ days-1 year & $1949(62.5 \%)$ \\
\hline $1-4$ years & $4164(60.2 \%)$ \\
\hline $5-9$ years & $4403(53.0 \%)$ \\
\hline $10-14$ years & $4953(47.6 \%)$ \\
\hline $15-19$ years & $6861(47.6 \%)$ \\
\hline Length of hospital stay - median days $($ min - max $)$ \\
\hline 28 days-1 year & $13.25(10-15.2)$ \\
\hline $1-4$ years & $9.95(7.3-11.1)$ \\
\hline $5-9$ years & $8.7(8.5-9.5)$ \\
\hline $10-14$ years & $9.4(9.1-9.9)$ \\
\hline $15-19$ years & $9.35(8.7-9.8)$ \\
\hline Mortality rate - median (min - max) & \\
\hline 28 days-1 year & $15.59(12.58-17.42)$ \\
\hline $1-4$ years & $3.38(2.50-3.89)$ \\
\hline $5-9$ years & $2.58(1.44-2.74)$ \\
\hline $10-14$ years & $2.72(2.70-2.91)$ \\
\hline $15-19$ yr & $3.97(3.94-5.01)$ \\
\hline & \\
\hline & \\
\hline
\end{tabular}

Table 1: Demographic characteristics of patients with renal failure from 1998 through 2007, according to age group excluding neonatal period.

mortality as deaths in late neonatal period (between 7th and 28th day of life). Post neonatal mortality as deaths after 28 days but within the first year of life. The children is defined, as patients who were 19 years old or less, include neonatal period ( 0 to 27 days). The ages were categorized into five age groups, analyzing the life cycles. In the primary database in: 28 days to under 1 year old, 1 to 4 years old, 5 to 9 years old, 10 to 14 years old and 15 to 19 years old, criterion adopted by the Brazilian database. In the secondary form newborn, two additional categories are available: from 0 to 6 days, 7 to 27 days.

\section{Statistical analyses}

Annual data were stratified into six subperiods (from 1998 through 1999, 2000 through 2001, 2002 through 2001, 2002 through 2003, 2004 through 2005, 2006 through 2007) for assessment of demographic changes among periods. Normal distribution tested by KolmogorovSmirnov test. We compared means using the Student's $t$ test when normally distributed and Mann-Whitney U test when not. Comparisons across multiple periods were calculated using Repeated Measures Analysis of Variance test. A p value of less than 0.05 was considered significant. Statistical analyses were done using SPSS for Windows version 15.0, EXCEL 2002 and MedCalc for Windows, version 9.5.0.0.

\section{Results}

During the study period, we identified 34,308,833 hospital admissions in children in Brazil. Kidney diseases (acute nephritic syndrome, rapidly progressive nephritic syndrome, others glomerular diseases, others tubulointerstitial diseases, renal failure) were reponsable by 666,725 admissions and kidney failure (acute kidney failure and chronic kidney failure) by 43,174 admissions.

\section{Demographics}

Admissions of renal failure: The overall hospitalizations from 1998

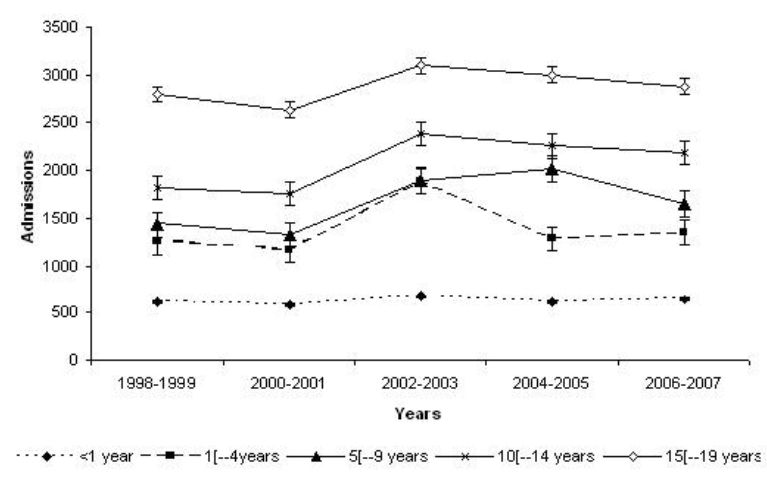

Figure 1: Renal failure hospital admissions, in according to age group (excluded neonatal period) and cohorts. Normal distribution tested by Kolmogorov-Smirnov test. Repeated measures anova; $\mathrm{F}=162.37$ $\mathrm{p}=0.000$.

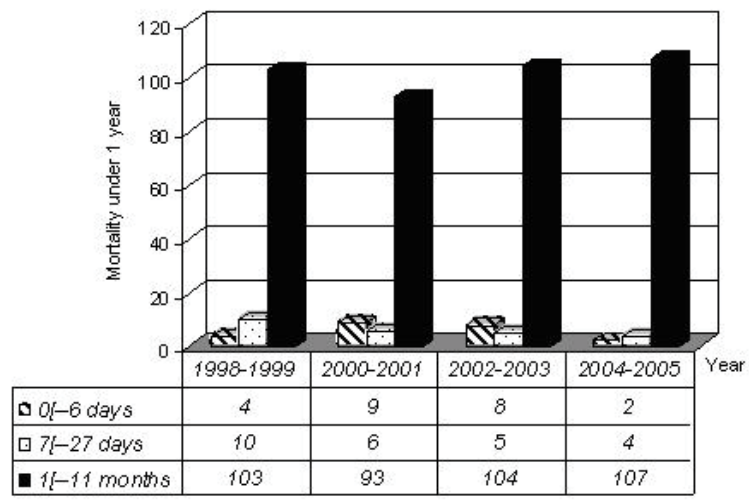

Figure 2: Renal failure hospital mortality under 1 year (included neonata period) from 1998 throught 2005, according to cohort with disponable data. 0[-6 days: Early neonatal mortality (within first week of life). 7[-28 days: Late neonatal mortality (between 7th and 28th day of life). 1 month [-11 months: Post neonatal mortality (after 28 days but within the first year of life). Mortality neonatal period 0 [-28 days versus 28 days [ -1 year, difference $-18,746(95 \%$ $\mathrm{Cl}$ for difference ; $-95,88$ to $-76,12)$.Student t-test $\mathrm{p}=0.000$.

through 2007 of kidney failure was $8.635+565$ cases, between 28 days to 1 year was $623.6 \pm 25.5$, from 1 year under 5 years was $1384.4 \pm 70$ and between 10 to 19 years was $2.350+749.53$ corresponding to $57,5 \%$ of all these admissions (Figure 1). The occurrence in boys was 22,330 cases or $51.7 \%$ of cases. Boys had not a significantly episodes of renal failure than girls $(\mathrm{p}>0.05)$. The overall mortality was 1,778 cases before discharge (Figure 2). The median of mortality rate between cohorts was 4.01 (3.87-4.73). In children between 28 days to 1 year, median of mortality rate was 13.25 (10-15.2) (Figure 3), in children from 1 year under 5 years was 3.38 (2.50-3.89). The post neonatal mortality (deaths after 28 days but within the first year of life) secondary to kidney failure was $87.3 \%$ higher than neonatal period (difference,-18.746 [95\% CI for difference; -48.99 to -38.98 ]; $\mathrm{p}=0.00$ ).

Congenital malformation of the urinary system in neonatal period: In addition, we studied in the birth the congenital malformations of the renal system as a potential disease that may lead to renal failure in post-natal period (Figure 4). We observed that 


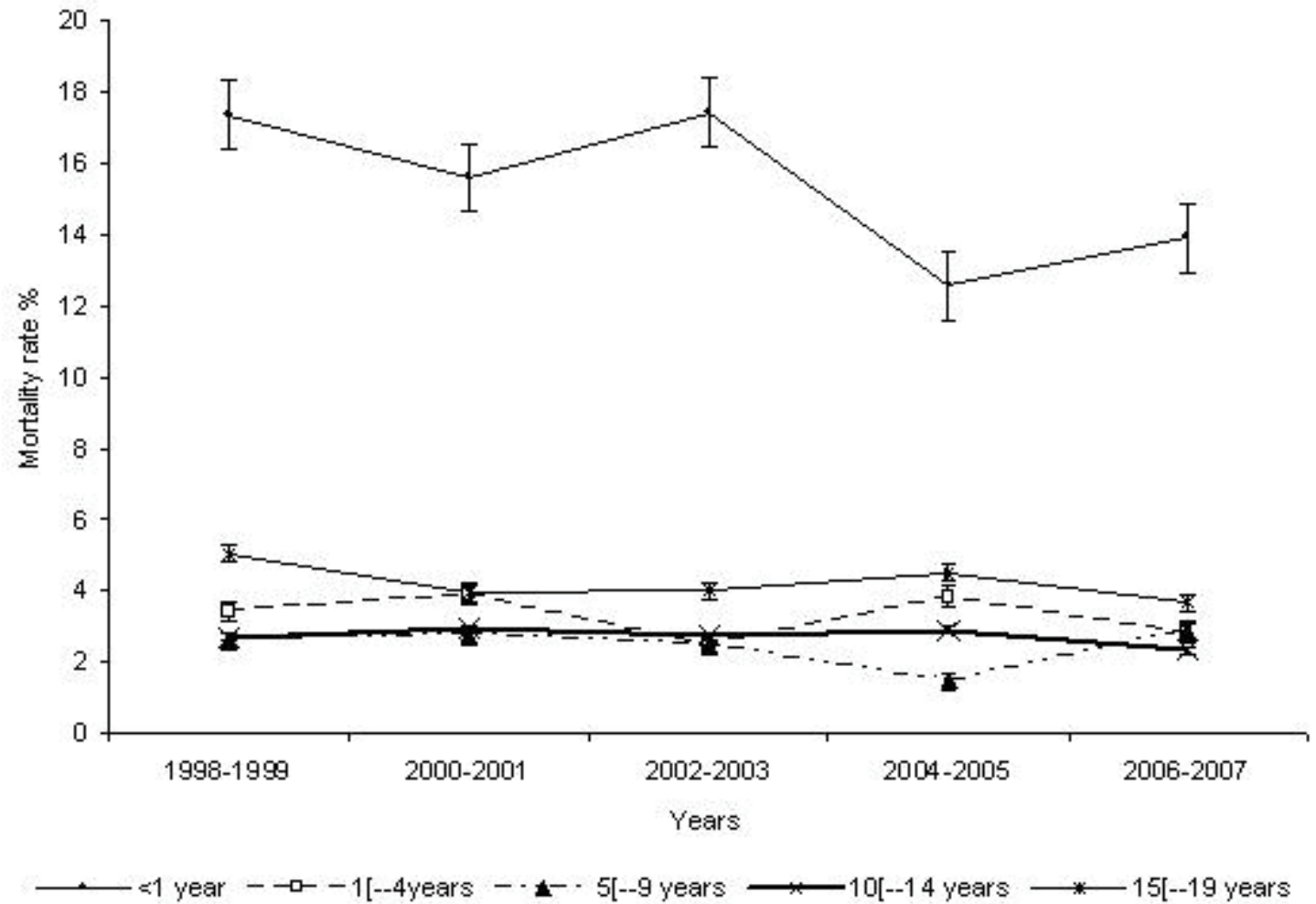

Figure 3: Renal failure hospital mortality rate, in according to age group (excluded neonatal period) and cohorts. The median of mortality rate 1 year (15.59\%) was 5 fold more than others age groups (3.05\%). Mann -Whitney rank sum test: $p=0.00$.

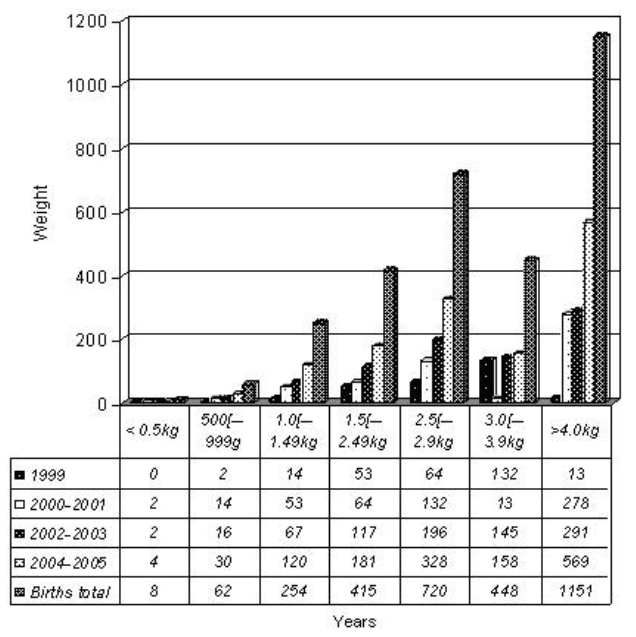

Figure 4: Incidence of congenital malformations of the urinary system (Q60-Q64) according to weight birth and cohort from 1999 throught 2005 Repeated measures anova; $F=4.60 p=0.015$.

congenital malformations of the urinary system was highest in infants with gestational age from 37 to 42 weeks (1435 births) and decrease in children with gestational age under 37 weeks (464 births). The coefficient of incidence of congenital malformations in the year 1999

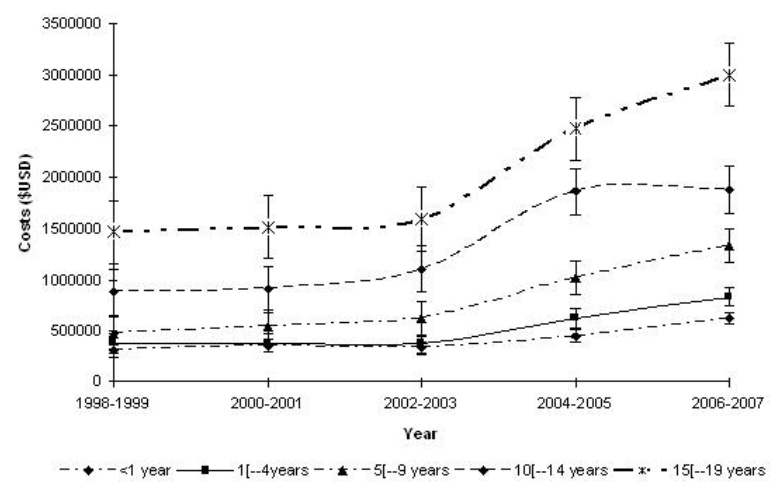

Figure 5: Hospital direct costs of kidney failure (\$USD) by age group and cohorts. (Repeated measures ANOVA: $F=12,48 ; p=0.000$ ).

was $0.08 / 1000$ inhabitants or 4 fold less than 2005 where the coefficient of incidence was $0.44 / 1000$ inhabitants (difference -0.36 [95\% CI for difference: -0.422 to -0.298$]$ )

Length of Hospital stay and direct costs: The median of length of stay (LOS) were 9.4 days (8.7-9.9) with national estimates among periods of 409,006 hospital days. The mean of hospital costs per year were $\$ 5,075,641 \pm 1,872,602.38$ millions of dollar with costs of the $\$ 588$ \pm 199.55 dollar per patient. The costs from the first period to the last 
period improve $50 \%$ ie, from $\$ 446$ dollar per patient in the first period 1998-1999 to \$881dollar per patient in the last period (Figure 5).

Renal failure by regions of Brazil: The hospital admissions were different among regions, in the last period, there were 603 admissions in north region; 2,198 in northeast; 3,255 in southeast; 1,225 in south and 1,428 in central west. In regional terms, the overall mortality rates and under one year were: north region $(6.80 \%$ and $22.58 \%$, respectively), northeast (3.96\% and $13.41 \%)$, southeast $(4.24 \%$ and $15.88 \%$, respectively), south (3.43\% and $17.71 \%$, respectively) and central west (1.61\% and $5.63 \%$, respectively). The southeast region that is the considerable less vulnerable region of Brazil where is localized State of São Paulo that is only brazilian state with child development index (CDI) classify as " high child-development" index category, with a CDI rating of 0.80 and high human development index of 0.78 . The overall mortality rate and under one year of kidney failure were high ie, $4.05 \%$ and $18.13 \%$, respectively.

\section{Discussion}

In our study, we found that kidney failure was responsible for 8,635 \pm 565 admissions in all children younger than 19 years old in Brazil, with range by age group of $623.6 \pm 25.5$ to $2,350 \pm 749.53$. The highest proportion attributed to kidney failure hospitalization occurred among children between 10 to 19 years (57.5\%) and in boys $51.7 \%$. The study is the first in our country to look at kidney failure investigating hospitalizations in a national database. The study also broke down hospitalization by age categorized into five age groups, analyzing the life cycles, by region and by six subperiods (from 1998 through 1999, 2000 through 2001, 2002 through 2001, 2002 through 2003, 2004 through 2005,2006 through 2007) in order to explore demographic tendency among age groups, regions of Brazil and periods. The proportion of hospitalizations caused by kidney failure among children younger than one year was $7.2 \%$, between 1 year to 4 years (16\%), 5 to 9 years $(19.3 \%)$, 10 to 14 years $(24.1 \%), 15-19$ years (33.4\%). The high proportion of admissions in adolescents may reflect the admissions associated with acute exacerbation of chronic kidney disease [8]. A recent unicenter study about epidemiology of renal failure in children reported occurrence of acute kidney failure, chronic kidney failure and unclassified kidney failure respectively in $28.6 \%, 2.5 \%$ and $68.9 \%$ of cases. In the study, admission average of age was $6.7 \pm 3.4$ years old, the average of length hospital stay was $10.2 \pm 10.1$ days and mortality rate $10.1 \%$ [9]. Our study observed similar characteristics of length hospital stay with median 9.4 but mortality rate was high under one year old in our study (15.65\%) however in age equivalent to the above study rates were lower from 1 year to 4 years the median of mortality rate was $3.28 \%$ and from 5 years to 9 years the median was $2.58 \%$. Few publications are available on morbidity of acute and chronic renal disease pediatric population, this problem is particularly important in hospital and critical care setting where early recognize of renal failure is important as a form to minimize sequels [10]. Therefore, administrative data sets have become essential resources for epidemiologic investigations in which the prospective identification of patients is not feasible [11]. Several studies by several authors of acute kidney failure and chronic kidney failure have reported variable incidence and variable between countries [12-15]. This large variability among studies could be explained by the lack of consensual definitions of acute kidney failure (AKF) that remains elusive, and commonly used definition, including biochemical aspects as high levels of creatinin, oliguria and azotemia, have shortcomings in pediatric practice. Although oliguria is often a presenting feature, it is variable; additionally creatinine levels and diuresis are individually a poor indicator of kidney function. AKF is often asymptomatic and noted only on routine screening laboratory evaluation as elevated blood urea nitrogen and creatinine levels, which are also insensitive markers of kidney function [11]. Also, several epidemiological studies of chronic renal failure are about adult population, limiting an sooner approach when it occurs at earlier stages of life as children and adolescents. We note that in this age, studies of chronic renal failure are rare, usually centered in end stage renal disease [8]. Unfortunately, due to exploratory feature of our study was not possible to determine through the Brazilian national database the prevalence of chronic renal failure in pediatric patients. Since our study is based on a national database and the base information is ICD 10 code, we hypothesize that we will found significant limitations as differences in hospitalization practices, applications of case definition. Moreover, ICD 10 code in our database didn't includes a chapter about chronic kidney failure, therefore a bias in our study. Additionally, we note that our database has the same tab profile of the European Hospital Morbidity Database (HMDB), but this database contains additional information on chronic renal failure [16]. However, both database present a limitation on the case definition of chronic kidney disease (CKD), which may include two concepts: a kidney damage over 3 months, defined by structural or functional abnormalities with or without decreased glomerular filtration rate (GFR) or GFR under to $60 \mathrm{ml} / \mathrm{min} / 1,73 \mathrm{~m}^{2}$ over 3 months. These concepts become an additional problem for large epidemiological studies [12]. We observed that congenital malformations of the urinary system was highest in infants with gestational age from 37 to 42 weeks and decrease in children with gestational age under 37 weeks, meaning that gestational age has a short impact in this type of malformations. Congenital malformation had overall mortality rate of 5.6\%. Congenital abnormalities of kidney and urinary tract have been observed frequently in children and represent a significant cause of morbidity and mortality. Data from birth defects registries indicate an overall frequency from two to three per 1,000 births, and the abnormalities seriously affect life expectancy [13]. This impact on survival might justify the high mortality rate of $15.6 \%$ in children under 1 year. However, this hypothesis is speculative because in our knowledge no global estimate of renal failure burden in pediatric population in low and middle income countries have been published to date. The admissions were different in Brazilian regions, having been high in the southeast region. By region, the mortality rate under 1 year and in post natal period was very high, same in regions with high CDI index, reasserting that this age group is vulnerable for death due to renal failure. In the southeast region, the less vulnerable region of Brazil, where is localized State of São Paulo, the mortality rate in the renal failure was high, $18.13 \%$. São Paulo is an industrialized state and Brazilian reference in hospital care mainly for families that need renal replacement therapy for their children and perhaps this fact explains the high mortality in this region [8]. Furthermore, our data are showing that renal failure has had a high morbidity from infancy to adolescence and this impact has been reflected by the high number of admissions from 10 to 19 years old or $57.5 \%$ of all hospital admissions, might reflecting high frequency of cases with chronic renal failure after 10 years of age as recently published in Brazil [8]. The costs from the first period to the last period increased substantially in 50\%, from $\$ 446$ dollar in the first period 1998-1999 to $\$ 881$ dollar in the last period. This data reinforces preliminary studies linking Brazilian public health system (SUS) as the main source of funds of renal replacement therapy in hospitalized patients [8,17]. As observed in our study, kidney failure is an important public health problem, considering its high prevalence from childhood to adulthood and its association with a high risk of mortality and sequel as chronic kidney failure, which has consequently high impact in the public health system costs [14]. Efforts are being 
undertaken to establish a consensus definition of ARF and to distinguish between varying degrees of acute kidney injury, real prevalence, incidence, treatment, morbidity and mortality [2,15,18]. There is ongoing recognition of the important interaction between ARF and chronic kidney disease in infants, children and adolescents [18-21]. Furthermore, the establishment of an task force will be taken as the Adult Acute Dialysis Quality Initiative and the Kidney Disease Outcomes Quality Initiative (K/DOQI) of the National Kidney Foundation (NKF) to our better understand of the real impact of acute and chronic kidney diseases in childhood and its long-term outcome [2,22-25]. In conclusion, our findings will expand knowledge of the impact of kidney failure in pediatric population. Our data may also stimulate global initiatives and researches agenda to understand better the real burden of kidney failure in children and adolescents allowing earlier diagnostic criteria and consequently faster therapeutic approach for these patients, mainly in population of low and middle-income countries.

\section{Authors Contributors}

Andrade MC, Mangia CMF, wrote the design of the study, contributed with ideas, carried out the cohort study, performed the statistical analysis and wrote the manuscript. The article was revised and approved by all contributors.

\section{Conflict of Interest Statement}

We declare that we don't have conflict of interests.

\section{Funding}

This study was conducted without external financial support.

\section{References}

1. Hoste EA, Kellum JA (2006) Acute kidney injury: epidemiology and diagnostic criteria. Curr Opin Crit Care 12: 531-537.

2. Bellomo R, Ronco C, Kellum JA, Mehta RL, Palevsky P (2004) Acute Dialysis Quality Initiative workgroup (2004) Acute renal failure - definition, outcome measures, animal models, fluid therapy and information technology needs: the Second International Consensus Conference of the Acute Dialysis Quality Initiative (ADQI) Group. Crit Care 8: R204-212.

3. Arruda TA, Amorim MM, Souza AS (2008) [Mortality caused by congenita anomalies in Pernambuco, Brazil from 1993 to 2003]. Rev Assoc Med Bras 54: $122-126$.

4. Agras PI, Tarcan A, Baskin E, Cengiz N, Gürakan B, et al. (2004) Acute renal failure in the neonatal period. Ren Fail 26: 305-309.

5. Sanghvi KP, Merchant RH, Gondhalekar A, Lulla CP, Mehta AA, et al. (1998) Antenatal diagnosis of congenital renal malformations using ultrasound. J Trop Pediatr 44: 235-240.

6. Ministry of Health. Health Information. Bank of the Unified Health System data

7. Brazilian Institute Of Geography and Statistics. Censuses.

8. Nogueira PCK, Feltran LS, Camargo MF, Leão ER, Benninghoven JRCS, et al (2011) Prevalencia estimada da doença renal cronica terminal em crianças no Estado de São Paulo. Rev Assoc Med Bras 57: 443-449.

9. Coulibaly G, Hamidou S, Evariste BB, Roger KA, Fla K, et al. (2016) Epidemiology of renal failure in children at the pediatric university hospital Charles De-Gaulle of Ouagadougou ( Burkina Faso). Open O J Ped 6: 141-148.
10. Uchino S (2006) The epidemiology of acute renal failure in the world. Curr Opin Crit Care 12: 538-543.

11. Martin GS, Mannino DM, Eaton S, Moss M (2003) The epidemiology of sepsis in the United States from 1979 through 2000. N Engl J Med 348: 1546-1554

12. Bagga A, Bakkaloglu A, Devarajan P, Mehta RL, Kellum JA, et al. (2007) Improving outcomes from acute kidney injury: report of an initiative. Pediatr Nephrol 22: 1655-1658.

13. Hogg RJ, Furth S, Lemley KV, Portman R, Schwartz GJ, et al. (2003) National Kidney Foundation's Kidney Disease Outcomes Quality Initiative Clinical Practice Guidelines for Chronic Kidney Disease in Children and Adolescents: Evaluation, Classification, and Stratification. Pediatrics 111: 1416-1421.

14. Edmonds LD, James LM (1990) Temporal trends in the prevalence of congenita malformations at birth based on the birth defects monitoring program, United States, 1979-1987. MMWR CDC Surveill Summ 39: 19-23.

15. Palevsky PM (2006) Epidemiology of acute renal failure: the tip of the iceberg Clin J Am Soc Nephrol 1: 6-7.

16. WHO (2015) The European Hospital Morbidity Database. World Health Organization Regional Office for Europe.

17. Sesso R, Lopes AA, Thome FS, Bevilacqua JL, et al. (2008) Relatorio do Censo Brasileiro de Dialise, 2008. J Bras Nefrol 30: 233-238.

18. Bellomo R (2006) The epidemiology of acute renal failure: 1975 versus 2005 Curr Opin Crit Care 12: 557-560.

19. Mehta RL, Chertow GM (2003) Acute renal failure definitions and classification time for change? J Am Soc Nephrol 14: 2178-2187.

20. Cole L, Bellomo R, Silvester W, Reeves JH (2000) A Prospective, Multicenter Study of the Epidemiology, Management, and Outcome of Severe Acute Renal Failure in a "Closed" ICU System. Am J Respir Crit Care Med 162: 191-196.

21. Uchino S, Kellum JA, Bellomo R, Doig GS, Morimatsu H, et al. (2005) Acute renal failure in critically ill patients: a multinational, multicenter study. JAMA 294: 813-818.

22. Williams DM, Sreedhar SS, Mickell JJ, Chan JC (2002) Acute kidney failure: a pediatric experience over 20 years. Arch Pediatr Adolesc Med 156: 893-900.

23. Cruz DN, Bolgan I, Perazella MA, Bonello M, de Cal M, et al. (2007) North East Italian Prospective Hospital Renal Outcome Survey on Acute Kidney Injury (NEiPHROS-AKI): targeting the problem with the RIFLE Criteria. Clin J Am Soc Nephrol 2: 418-425.

24. Bagshaw S, George C, Bellomo R (2008) Early acute kidney injury and sepsis: a multicentre evaluation. Crit Care 12: R47- R56.

25. Rivera F, López-Gómez JM, Pérez-García R (2002) Spsnish Registry of Glomerulonephritis. Frequency of renal pathology in Spain 1994-1999. Nephro Dial Transplant 17: 1594-1602. 